\title{
Relative Energy Deficiency in an Elite Professional non-Endurance Male Caused by Short Period of Overtraining and Caloric Restriction: A Case Report
}

\section{Yun Zhou}

Peking university first hospital https://orcid.org/0000-0002-5107-9498

Nan Gu ( $\nabla$ nan.gu@pkufh.cn )

Peking University First Hospital https://orcid.org/0000-0001-9852-0060

\section{Wei Wang}

Peking University First Hospital

\section{Ying Gao}

Peking University First Hospital

Junqing Zhang

Peking University First Hospital

\section{Case report}

Keywords: hypogonadotropic hypogonadism, relative energy deficiency in sport, male athlete, case report, COVID-19

Posted Date: November 17th, 2020

DOI: https://doi.org/10.21203/rs.3.rs-104721/v1

License: (c) (1) This work is licensed under a Creative Commons Attribution 4.0 International License. Read Full License 


\section{Abstract}

Background: Relative energy deficiency in sports (RED-S) is well-recognized in women competing in endurance sports; however, it is less common in males competing in non-endurance sports. Here, we report a case of hypogonadotropic hypogonadism associated with RED-S in an elite male non-endurance skill athlete caused by a change in workout over a short time frame.

Case presentation: An 18-year-old elite male non-endurance skill athlete complained of fatigue, depression, and inattention. Blood tests showed low total testosterone levels and a physical examination revealed Tanner stage phase IV-V. A gonadotropin-releasing hormone (GnRH) stimulation test revealed that the luteinizing hormone (LH) level was 10 times above normal, suggesting hypothalamic hypogonadism. However, magnetic resonance imagings (MRI) of pituitary gland, brain, and adrenal glands were normal. Due to COVID-19 pandemic, he was quarantined for 2 weeks. During that time, he only performed a basic workout. At the end of quarantine, his coach made him follow a new training program that was $>50 \%$ more intense than the one before quarantine. He also had to restrict calorie intake for snowboarding. He was diagnosed as relative energy deficiency in sport (RED-S). The condition resolved after lifestyle and training modifications.

Conclusions: RED-S is not restricted to endurance athletes. Elite athletes performing non-endurance sports can also suffer from it after a significant modification of training. Sports scientists/trainers should monitor caloric intake and training intensity to avoid RED-S, protect the health and improve the performance of all athletes.

\section{Introduction}

Relative energy deficiency in sport is a well-recognized condition in women and men competing in endurance sports ${ }^{[1]}$. However, the condition is much less common in male athletes competing in nonendurance sports. One symptom of RED-S is hypogonadotropic hypogonadism. The mechanism underlying hypogonadotropic hypogonadism is unclear ${ }^{[1]}$; however, some have suggested that low energy availability (LEA) plays a role ${ }^{[2]}$. Furthermore, there is no consensus regarding treatment. Here, we describe an adolescent male non-endurance athlete who presented with loss of appetite, depression and loss of concentration after undertaking 2 months of intense physical fitness training.

\section{Case Presentation}

An 18-year-old elite male non-endurance skill athlete was transferred to our endocrine ward with a 3month history of fatigue, depression and inattention. He also suffered dizziness during nocturnal urination. Due to COVID-19 (coronavirus disease) pandemic, he was quarantined for 2 weeks as a precaution. After quarantine, he followed a strength training program designed by his coach. However, the training program was different from his previous comprehensive outdoor training program; indeed, the patient thought that the intensity of the new training program was $50 \%$ (or more) higher than that of his 
previous plan. He reported no visual field defects or headache. Further questioning revealed no obvious reduction in libido or absence of morning erections. He stated that he was on a calorie-controlled diet to regulate his weight for performance. He was born by cesarean due to fetal macrosomia but his mother did not report gestational diabetes mellitus during pregnancy. His pediatric developmental history was unremarkable, with normal puberty and onset of secondary sexual characteristics. This was also true for both his mother and father.

He showed low total testosterone levels in a test taken 2 years ago, but it recovered to normal at the time of a follow-up test. He was in good health prior to onset of the present symptoms. He denied using any drugs including performance-enhancing drugs.

Physical examination revealed Tanner stage phase IV-V. His body mass index was $21.436 \mathrm{~kg} / \mathrm{m}^{2}$. Gonadal examination revealed normal testicles and genitalia, with standard sexual characteristics. Testicular examination revealed normal testes $(\sim 20-25 \mathrm{~mL})$, a normal phallus, and no other abnormalities. The rest of the examination was unremarkable.

Laboratory tests revealed low total testosterone levels $(254.8 \mathrm{pg} / \mathrm{ml}$; normal range, $3000-12000 \mathrm{pg} / \mathrm{ml})$, reduced free testosterone $(4.9 \mathrm{pg} / \mathrm{ml}$; normal range, $42.6-164.0 \mathrm{pg} / \mathrm{ml})$, and a normal gonadotrophin levels. This led to a diagnosis of hypogonadotropic hypogonadism. Levels of hormones are listed in Table 1. Energy availability was $10.44 \mathrm{kcal} / \mathrm{kg}$.fat free mass (FFM)/day and body fat (BF) was $9.7 \%$. Bone density in the lateral hips and bone age of the left hand were within normal limits. Ultrasound of testes and thyroid, MRIs of brain, pituitary and adrenal glands were normal. 
Table 1

Laboratory values at 1 month before admission, at admission, and at 2-month follow-up

\begin{tabular}{|c|c|c|c|}
\hline $\begin{array}{l}\text { Laboratory test } \\
\text { (normal rage) }\end{array}$ & 1 month before admission & At admission & $\begin{array}{l}\text { At 2-month follow- } \\
\text { up }\end{array}$ \\
\hline $\begin{array}{l}\text { Total testosterone } \\
(1.75-7.81) \mathrm{ng} / \mathrm{ml}\end{array}$ & $\begin{array}{l}254.8(3000- \\
12000) \mathrm{pg} / \mathrm{ml}\end{array}$ & $0.43 \mathrm{ng} / \mathrm{ml}$ & $3.97 \mathrm{ng} / \mathrm{ml}$ \\
\hline Free testosterone & $\begin{array}{l}4.9 \\
(42.6-164.0) \mathrm{pg} / \mathrm{ml}\end{array}$ & $\begin{array}{l}2.23 \\
(15-50) \\
\mathrm{pg} / \mathrm{ml}\end{array}$ & \\
\hline PRL (2.64-13.13) ng/ml & & 13.32 & 8.25 \\
\hline $\mathrm{LH}(1.24-8.62) \mathrm{mlU} / \mathrm{ml}$ & & 1.6 & 4.5 \\
\hline $\mathrm{FSH}(1.27-19.26) \mathrm{mIU} / \mathrm{ml}$ & & 2.38 & 3.87 \\
\hline $\mathrm{GH}(0.03-2.47) \mathrm{ng} / \mathrm{ml}$ & 1.66 & 0.455 & 1.040 \\
\hline IGF-1 $(163-584) \mathrm{ng} / \mathrm{ml}$ & & 318 & \\
\hline $\begin{array}{l}\text { 8AM cortisol (6.2-19.4) } \\
\mu \mathrm{g} / \mathrm{dl}\end{array}$ & & 16.15 & 12.87 \\
\hline 8AM ACTH $(7.2-63.3) \mathrm{pg} / \mathrm{ml}$ & & 24.46 & 27.37 \\
\hline $\mathrm{T} 3(1.2-3.2) \mathrm{nmol} / \mathrm{L}$ & $\begin{array}{l}0.49 \\
(0.8-1.90) \mathrm{pmol} / \mathrm{L}\end{array}$ & 0.68 & 1.92 \\
\hline FT3 (3.5-6.5) pmol/L & 2.84 & 2.61 & 5.79 \\
\hline $\mathrm{T} 4(54.1-151.9) \mathrm{nmol} / \mathrm{L}$ & & 62.1 & 82.2 \\
\hline FT4 (11.48-22.7) pmol/L & & 12.51 & 14.94 \\
\hline $\mathrm{TSH}(0.55-4.78) \mathrm{ulU} / \mathrm{ml}$ & & 0.548 & 0.46 \\
\hline
\end{tabular}

A gonadotropin-releasing hormone $(\mathrm{GnRH})$ stimulation test revealed a luteinizing hormone (LH) level 10 times above normal (Fig. 1), demonstrating hypothalamic hypogonadism.

Further extensive workup including pituitary, hypothalamus and brain MRIs did not identify the underlying cause of hypogonadism. Therefore, he was diagnosed with RED-S. After discussions with his coach and mother, he was advised to reduce the frequency and intensity of the training and modify the caloric intake. He stopped training and returned to a lower ranked team. His condition improved 2 months later 
and didn't have any complains with no additional interventions. Testosterone and thyroid function had recovered to normal (Table 1).

\section{Discussion}

Exercise-related dysfunction of the hypothalamic-pituitary axis was reported in women decades ago; the condition was called the Female Athlete Triad ${ }^{[3]}$. Similar dysfunction in males was confirmed 30 years ago. Men who in the past had been running at least $64 \mathrm{~km}$ per week had significantly lower serum total testosterone and free testosterone levels than sedentary controls ${ }^{[4]}$. Subsequent reporting of more cases and the results of clinical trials led renaming of this type of dysfunction as RED-S. RED-S refers to impaired physiological functions, including but not limited to metabolic rate, menstrual function, bone health, immunity, protein synthesis, and cardiovascular health. The cause is energy deficiency due to an imbalance between dietary intake and energy expenditure required for health and activities of daily living, growth, and participation in sporting activities. Psychological sequelae can either precede RED-S or be the result of RED-S ${ }^{[5]}$. The majority of the literature examining RED-S in males has focused on cyclists, rowers, runners, jockeys, and athletes competing in combat sports; the common thread here seems to be the need to control body weight within strict parameters to optimize performance ${ }^{[1]}$. There are few reports of RED-S in athletes competing in non-endurance sports. Without large-scale epidemiological studies in this area, data from male athletes is in short supply ${ }^{[6]}$. The RED-S model considers energy deficiency/low energy availability (LEA) as the central cause $\mathrm{e}^{[7,8]}$. A previous study suggests that a high percentage $(47.2 \%)$ of male athletes is at high risk for LEA ${ }^{[9]}$. Research has identified a standard LEA threshold for healthy active women; a diagnosis of LEA in women is based on an energy availability of $\leq$ $30 \mathrm{kcal} / \mathrm{kg} \cdot \mathrm{FFM} / \mathrm{day}{ }^{[5]}$. However, no such cut-off point has been identified for exercising men. Therefore, researchers have applied the female-based values to males ${ }^{[10]}$. Treatment of RED-S involves increasing energy intake, exercise reduction, or a combination of both, along with consultation with a mental health professional if needed ${ }^{[5]}$.

It is noteworthy that unlike previously reported cases of RED-S, the patient in this case was not competing in an endurance sport ${ }^{[11-13]}$; indeed, few cases of RED-S have been reported in male non-endurance athletes. Based on his symptoms and signs including low energy, normal phallus and testes, and normal male breast, he was diagnosed with postpubertal onset, secondary hypogonadism ${ }^{[14]}$. During his 14 -day quarantine, he only maintained a basic workout. Decrease of workout may not provide enough training stimuli and result in impaired performance ${ }^{[15]}$, and possibly trigger RED-S. The patient had very low LEA $(10.44 \mathrm{kcal} / \mathrm{kg} \cdot \mathrm{FFM} /$ day), resulting from reduced caloric intake and increased training intensity. The incidence of LEA in weight-restricted sports is high ${ }^{[7]}$. In our case, bone density was normal, which is unusual as a common finding in RED-S is loss of bone density ${ }^{[16]}$. This may indicate that the patient had an acute change. Thyroid hormone levels may have decreased to maintain body energy status, as seen in low T3 syndrome ${ }^{[7]}$. In addition, release of pituitary prolactin (a testosterone inhibitor) was increased,

which is associated with training-induced reductions in testosterone levels ${ }^{[17]}$. A previous literature review 
revealed that LEA causes psychological problems when a male athlete approaches the lower limit of BF $(4-5 \%)^{[18]}$. Prior to 2019 , our patient maintained a low BF level (6\%); thus, both low body fat levels and RED-S may have affected his mental health. He recovered after 2 months of reduced intensity exercise and increased caloric intake, which is in line with another study showing that testosterone levels return to normal within 5 weeks of reduced intensity training ${ }^{[19]}$.

In our case, the patient developed marked hypogonadism after increasing training intensity. Relative malnutrition was caused by excessive energy expenditure and reduced caloric intake. The fatigue and mental health problems were likely due to testosterone deficiency and intensive training. Taken together, the findings reported herein suggest that RED-S can occur in elite male athletes undertaking intense training coupled with restricted caloric intake. Thus, RED-S is not restricted to females and endurance athletes. Therefore, sports scientists/trainers should monitor caloric intake and training intensity to avoid the LEA and RED-S. Such measures will protect the health and improve the performance of all athletes.

\section{Abbreviations}

\section{RED-S}

Relative energy deficiency in sport

COVID-19

coronavirus disease

FFM

fat free mass

$\mathrm{BF}$

body fat

MRI

magnetic resonance imaging

PRL

prolactin

LH

luteinizing hormone

$\mathrm{FSH}$

follicle stimulating hormone

$\mathrm{GH}$

growth hormone

IGF-1

Insulin-like growth factor 1

ACTH

adrenocorticotropic hormone

T3

triiodothyronine 
FT3

free triiodothyronine

$\mathrm{T} 4$

tetraiodothyronine

FT4

free tetraiodothyronine

TSH

thyroid-stimulating hormone

$\mathrm{GnRH}$

gonadotropin-releasing hormone

LEA

low energy availability

\section{Declarations}

Ethics approval and consent to participate

Informed consent was obtained from the patient. A copy of the written consent is available for review.

Consent for publication

Not applicable.

\section{Availability of data and materials}

The data is available from the corresponding author upon reasonable request.

\section{Competing interests}

The authors declare that they have no competing interests.

\section{Funding}

Not applicable.

\section{Authors' contributions}

Yun Zhou collected data, made a diagnosis, gave treatment, and wrote the original draft. Nan Gu made a diagnosis, gave treatment and substantively revised the manuscript. All authors edited the manuscript and approved the final version of manuscript.

\section{Acknowledgements}

Not applicable. 


\section{References}

1. Mountjoy M, Sundgot-Borgen JK, Burke LM, Ackerman KE, Blauwet C, Constantini N, Lebrun C, Lundy $B$, Melin AK, Meyer NL, et al. IOC consensus statement on relative energy deficiency in sport (RED-S): 2018 update. British journal of sports medicine 2018.doi:10.1136/bjsports-2018-099193.

2. Kapczuk K. Elite athletes and pubertal delay. Minerva pediatrica. 2017. doi:10.23736/s00264946.17.05044-7.

3. Birch K. Female athlete triad. BMJ (Clinical research ed. 2005. doi:10.1136/bmj.330.7485.244.

4. Wheeler GD, Wall SR, Belcastro AN, Cumming DC. Reduced serum testosterone and prolactin levels in male distance runners. Jama 1984.

5. Mountjoy M, Sundgot-Borgen J, Burke L, Carter S, Constantini N, Lebrun C, Meyer N, Sherman R, Steffen K, Budgett R, et al. The IOC consensus statement: beyond the Female Athlete Triad-Relative Energy Deficiency in Sport (RED-S). British journal of sports medicine 2014.doi:10.1136/bjsports2014-093502.

6. Hooper DR, Tenforde AS, Hackney AC. Treating exercise-associated low testosterone and its related symptoms. The Physician and sportsmedicine 2018.doi:10.1080/00913847.2018.1507234.

7. Dipla K, Kraemer RR, Constantini NW, Hackney AC. Relative energy deficiency in sports (RED-S): elucidation of endocrine changes affecting the health of males and females. Hormones (Athens Greece). 2020. doi:10.1007/s42000-020-00214-w.

8. Logue DM, Madigan SM, Melin A, Delahunt E, Heinen M, Donnell SM, Corish CA. Low Energy Availability in Athletes 2020: An Updated Narrative Review of Prevalence, Risk, Within-Day Energy Balance, Knowledge, and Impact on Sports Performance. Nutrients 2020.doi:10.3390/nu12030835.

9. Lane AR, Hackney AC, Smith-Ryan A, Kucera K, Registar-Mihalik J, Ondrak K. Prevalence of Low Energy Availability in Competitively Trained Male Endurance Athletes. Medicina (Kaunas, Lithuania) 2019.doi:10.3390/medicina55100665.

10. Lane AR, Hackney AC, Smith-Ryan A, Kucera K, Registar-Mihalik J, Ondrak K. Prevalence of Low Energy Availability in Competitively Trained Male Endurance Athletes. Medicina 2019.

11. Korsten-Reck U, Seufert J, Dickhuth HH, Schumacher YO, König D. Hypogonadism and anemia in an athlete. International journal of sports medicine 2012.doi:10.1055/s-0031-1285927.

12. Narla A, Kaiser $K$, Tannock LR. EXTREMELY LOW TESTOSTERONE DUE TO RELATIVE. ENERGY DEFICIENCY IN SPORT: A CASE REPORT. AACE clinical case reports 2019.doi:10.4158/accr-20180345.

13. Naessens G, De Slypere JP, Dijs H, Driessens M. Hypogonadism as a cause of recurrent muscle injury in a high level soccer player. A case report. International journal of sports medicine 1995.doi:10.1055/s-2007-973030.

14. Salonia A, Rastrelli G, Hackett G, Seminara SB, Huhtaniemi IT, Rey RA, Hellstrom WJG, Palmert MR, Corona G, Dohle GR, et al. Paediatric and adult-onset male hypogonadism. Nat Rev Dis Primers 2019.doi:10.1038/s41572-019-0087-y. 
15. Sarto F, Impellizzeri FM, Spörri J, Porcelli S, Olmo J, Requena B, Suarez-Arrones L, Arundale A, Bilsborough J, Buchheit M, et al. Impact of Potential Physiological Changes due to COVID-19 Home Confinement on Athlete Health Protection in Elite Sports: a Call for Awareness in Sports Programming. Sports medicine (Auckland, NZ) 2020.doi:10.1007/s40279-020-01297-6.

16. Tenforde AS, Barrack MT, Nattiv A, Fredericson M. Parallels with the Female Athlete Triad in Male Athletes. Sports medicine (Auckland, NZ) 2016.doi:10.1007/s40279-015-0411-y.

17. Hackney AC, Sharp RL, Runyan WS, Ness RJ. Relationship of resting prolactin and testosterone in males during intensive training. British journal of sports medicine 1989.doi:10.1136/bjsm.23.3.194.

18. Fagerberg P. Negative Consequences of Low Energy Availability in Natural Male Bodybuilding: A Review. International journal of sport nutrition and exercise metabolism 2018.doi:10.1123/ijsnem.2016-0332.

19. Hackney AC, Hooper DR. Low testosterone: Androgen deficiency, endurance exercise training, and competitive performance. Physiology international 2019.

\section{Figures}
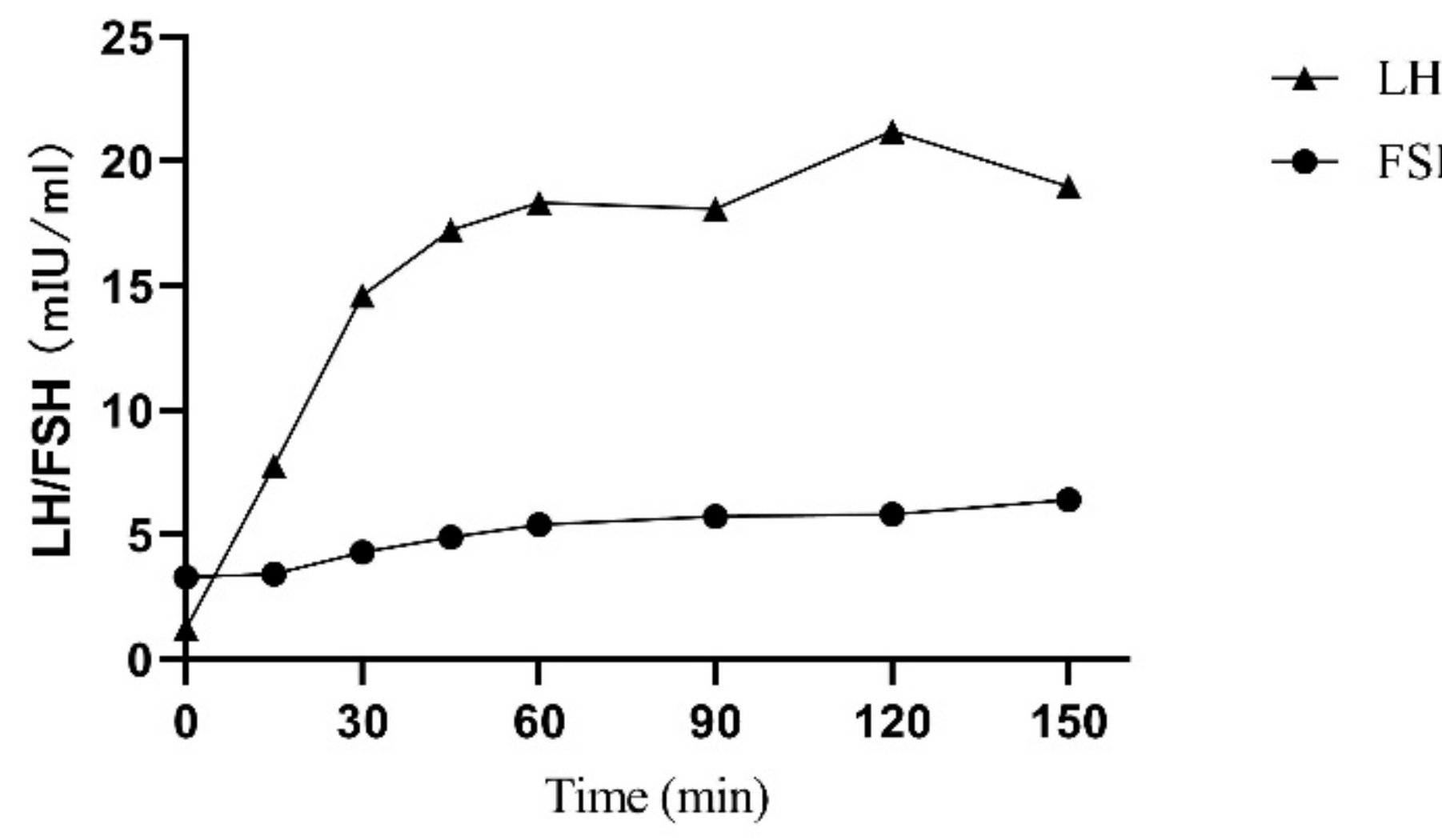

$\rightarrow \mathrm{FSH}$

Figure 1

GnRH stimulation test results. LH, luteinizing hormone; FSH, follicle stimulating hormone. 


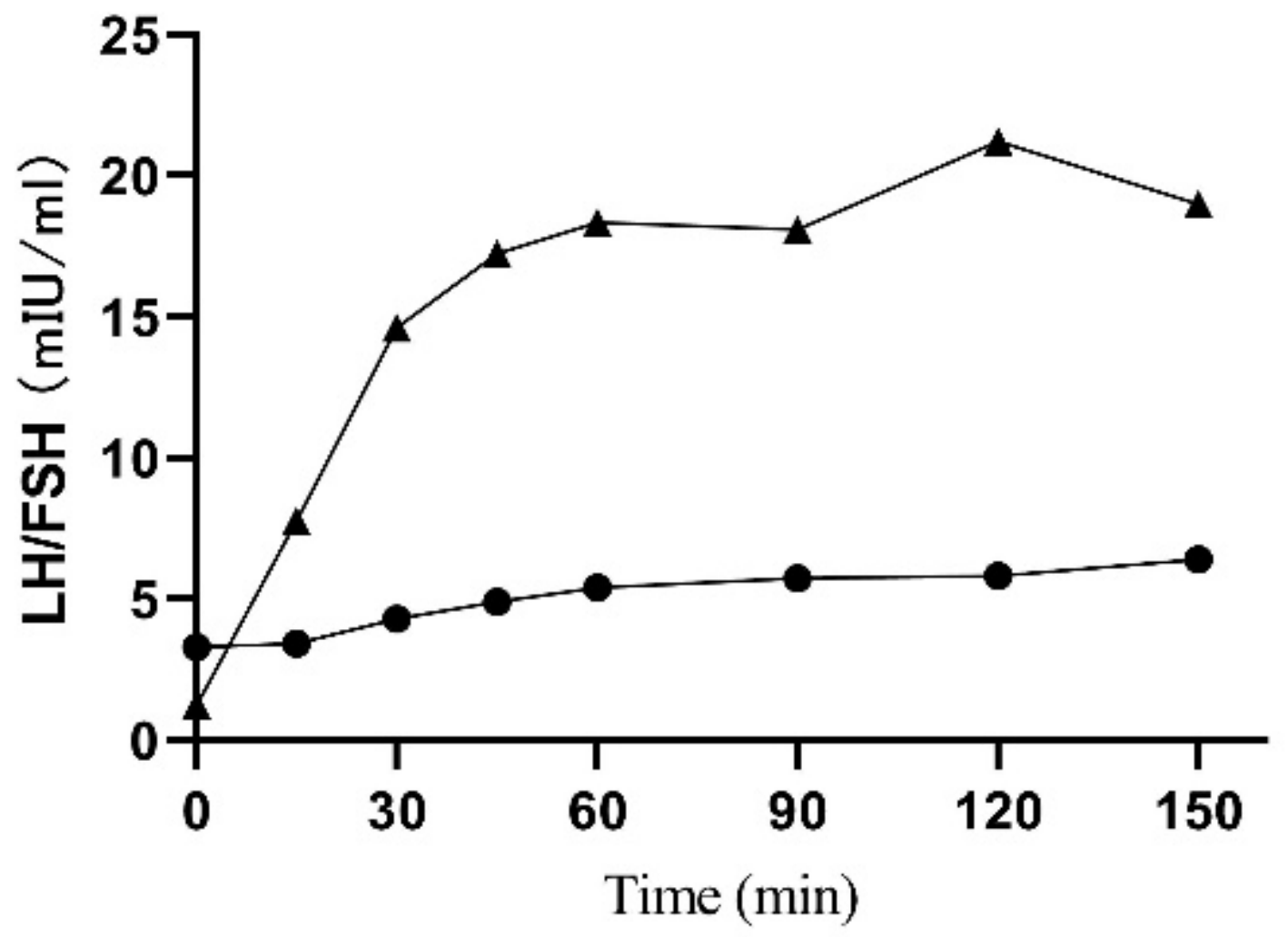

$\neg$ LH

$\rightarrow$ FSH

\section{Figure 1}

GnRH stimulation test results. LH, luteinizing hormone; $\mathrm{FSH}$, follicle stimulating hormone.

\section{Supplementary Files}

This is a list of supplementary files associated with this preprint. Click to download.

- CAREchecklistEnglish2013.pdf

- CAREchecklistEnglish2013.pdf 